\title{
Penerapan Metode TOPSIS \& SAW Dalam Pemilihan Destinasi Wisata Di Jawa Timur
}

\author{
Irfan Mahendra*, Adynoto Suprapto** \\ *, ** Program Studi Sistem Informasi, STMIK Nusa Mandiri \\ *Irfan.iha@nusamandiri.ac.id,** adynot11180819@nusamandiri.ac.id
}

\begin{abstract}
This research was conducted to test the application of the Technique Order Preference by Similarity to Ideal Solution (TOPSIS) method and the Simple Additive Weighting (SAW) method in the decision-making process of choosing tourist destinations in East Java. This research is motivated by the problems faced by the Jakarta Backpacker Community who often have difficulty in making choices about tourist destinations to be visited in East Java. The criteria used in this study are cost, destination, meeting point, trip length and facilities obtained. The results of this study indicate that The TOPSIS method and the SAW Method can be used for the decision-making process in the selection of tourist destinations in East Java, with the results of Explore Baluran and Menjangan being the most recommended choices as the primary choice. Besides, it is also known that there is a match between the TOPSIS and SAW methods, with the calculation results using the TOPSIS method that is 0.64 and the calculation using the SAW method is 0.86 as the highest calculated value. So as such, these two methods can be stated equally well used in the process of determining tourist destinations in East Java. However, this applies only to the highest value, because for the order of two and so on, the results of calculations on these two methods show differences in rank.
\end{abstract}

Keyword: tourist destinations, topsis method, saw method

\section{Introduction}

Provinsi Jawa Timur merupakan provinsi terluas di antara enam provinsi yang ada di Pulau Jawa, yaitu dengan luas wilayah $47.922 \mathrm{~km}^{2}$ dan memiliki jumlah penduduk sebanyak 39 juta jiwa, provinsi dengan jumlah penduduk terbanyak kedua di Indonesia setelah Jawa Barat [1]. Pada Triwulan II 2019 pertumbuhan ekonomi Jawa Timur mencapai 5,72 persen, di atas pertumbuhan ekonomi nasional yang hanya mencapai 5,05 persen. Pesatnya pertumbuhan ekonomi Jawa Timur ini didorong oleh pertumbuhan sektor ekonomi kreatif dan pariwisata [2]. Sektor pariwisata menjadi salah satu penyumbang Pendapatan Asli Daerah (PAD) di Provinsi Jawa Timur tahun 2019 yang sebesar Rp. 14,9 triliun . Wujud dari keberhasilan tersebut, Provinsi Jawa Timur menerima penghargaan kategori platinum dalam ajang Indonesia Attractiveness Award (IAA) 2019 dalam pelayanan publik dan pariwisata [3].

Berdasarkan data BPS Jatim, jumlah kunjungan wisman ke Jawa Timur pada Juli 2019 mencapai 25.143 kunjungan, naik 8,61 persen dibandingkan Juni 2019 yang hanya 23.150 kunjungan [4]. Selain menggunakan jasa pemandu wisata, saat ini banyak juga wisman yang datang ke Jawa Timur secara mandiri atau melalui komunitas backpacker. Prinsip utama berwisata ala backpacker atau yang dikenal dengan istilah backpacking ini adalah independent, travel light, educated, dan travel cheap [5].

Salah satu komunitas backpacker yang saat ini cukup aktif adalah Backpacker Jakarta. Komunitas yang bemarkas di Cawang, Jakarta Timur ini telah memiliki anggota lebih dari 3.400 orang. Backpacker Jakarta selalu rutin mengadakan perjalanan (trip) wisata, baik One Day Trip (ODT) maupun trip yang dilaksanakan lebih dari dua hari. Selain diikuti oleh member, Backpacker Jakarta juga membuka peluang bagi non member untuk ikut melakukan trip bersama, dengan sistem sharecost. Salah satu destinasi yang sering dikunjungi Backpacker Jakarta adalah Jawa Timur.

Pertimbangan Backpacker Jakarta memilih Jawa Timur, karena Jawa Timur memiliki destinasi wisata yang sangat menarik dan beragam, mulai dari wisata pantai, pulau, air terjun, gunung, hingga wisata sejarah dan hiburan. Saat ini ada beberapa destinasi di Jawa Timur yang sering dijadikan tujuan wisata oleh Backpacker Jakarta, diantaranya adalah Explore Malang, Explore Banyuwangi, Explore Pacitan, Explore Baluran \& Menjangan, serta Explore Lumajang \& Probolinggo.

Namun, dalam menentukan perjalanan wisata ke Jawa Timur, travelers seringkali mengalami kesulitan dalam mengambil keputusan dalam memilih destinasi yang akan dipilih. Hal ini selain karena banyaknya tujuan wisata yang dapat menjadi pilihan juga disebabkan oleh ada banyak faktor yang mempengaruhi keputusan travelers dalam memilih destinasi wisata, seperti biaya, waktu, fasilitas yang diberikan, dan jenis destinasinya. Sehingga dengan demikian dibutuhkan suatu sistem yang dapat membantu travelers dalam mengambil keputusan dalam memilih destinasi wisata, agar keputusan yang diambil dapat lebih optimal.

Berdasarkan beberapa penelitian terdahulu diketahui bahwa metode Technique Order Preference by Similarity 
to Ideal Solution (TOPSIS) dan Metode Simple Additive Weighting (SAW) merupakan metode yang banyak digunakan peneliti untuk mendukung proses pengambilan keputusan multikriteria sebagaimana di atas. Di antaranya adalah penelitian yang dilakukan oleh [6], [7], [8], [9], [10], [11], dan [12]. Berdasarkan hasil dari penelitian-penelitian tersebut menunjukkan kesesuaian penerapan Metode TOPSIS dan Metode SAW untuk mendukung pengambilan keputusan multi-kriteria.

Metode TOPSIS dan SAW sama-sama tergabung dalam model Multi-Attribute Decision Making (MADM), yaitu metode yang digunakan untuk mencari alternatif optimal dari sejumlah alternatif dengan kriteria tertentu. Selain itu, kedua konsep ini juga memiliki konsep yang sederhana, mudah dipahami, komputasinya efisien dan memiliki kemampuan untuk mengukur kinerja relatif dari alternatif-alternatif keputusan dalam bentuk matematis yang sederhana [13].

Metode TOPSIS merupakan salah satu metode pengambilan keputusan multikriteria yang pertama kali diperkenalkan oleh Kwangsun Yoon and Hwang Ching-Lai, yang menggunakan prinsip bahwa alternatif yang terpilih harus mempunyai jarak terpanjang dari solusi ideal negatif dari sudut pandang geometris dengan menggunakan kedekatan relatif dari suatu alternatif [14]. Sedangkan Metode Simple Additive Weighting (SAW) memiliki konsep dasar mencari penjumlahan terbobot dari rating kinerja pada setiap alternatif di semua atribut [15].

Berdasarkan paparan di atas, maka peneliti memandang bahwa Metode TOPSIS dan SAW dapat digunakan untuk mendukung proses pengambilan keputusan destinasi wisata di Jawa Timur, yaitu dengan memberikan bobot pada kriteria-kriteria, seperti destinasi, biaya, meeting point, lama trip, dan fasilitas.

\section{Research Method}

Metode yang digunakan di dalam penelitian ini adalah :

A. Metode Technique For Order Preference By Similarity To Ideal Solution

Technique For Order Preference By Similarity To Ideal Solution (TOPSIS ) adalah salah satu metode pengambilan keputusan multikriteria [16]. Metode TOPSIS menggunakan prinsip bahwa alternatif terpilih harus mempunyai jarak terdekat dari solusi ideal positif dan jarak terpanjang dari solusi ideal negatif untuk menentukan kedekatan relatif dari suatu alternatif dengan solusi optimal. Solusi ideal positif didefinisikan sebagai jumlah dari seluruh nilai terbaik yang dapat dicapai untuk setiap atribut, sedangkan solusi ideal negatif terdiri dari seluruh nilai terburuk yang dicapai untuk setiap atribut. Metode TOPSIS mempertimbangkan keduanya, jarak terhadap solusi ideal positif dan jarak terhadap solusi ideal negatif dengan mengambil kedekatan relative terhadap solusi ideal positif.

Adapun beberapa tahap dalam Metode TOPSIS, yaitu :

a. Membuat matriks keputusan yang ternormalisasi.

b. Membuat matriks keputusan yang ternormalisasi yang terbobot.

c. Membuat matriks solusi ideal positif dan negative

d. Menentukan jarak antara nilai setiap alternatif dengan matrik solusi ideal positif dan negative

e. Menentukan nilai preferensi untuk setiap alternatif.

- Decision Matrix D mengacu terhadap m alternatif yang akan dievaluasi berdasarkan kriteria yang didefinisikan.

- Dengan xij menyatakan performansi dari perhitungan untuk alternatif ke-i terhadap atribut ke - j.

Berikut langkah beserta rumus yang digunakan :

1. Membangun Normalized decision matrix.

$$
\begin{aligned}
\mathrm{R}_{\mathrm{ij}}= & \frac{x i j}{\sqrt{\sum_{i=1}^{m} x_{i j}^{2}}} \\
& \mathrm{i}=1,2,3, \ldots \mathrm{m} ; \text { dan } \mathrm{j}=1,2,3, \ldots \mathrm{n}
\end{aligned}
$$

2. Membangun Weight Normalized decision matrix. Solusi ideal positif dan negatif dapat ditentukan berdasarkan rating bobot ternormalisasi (Yij) sebagai :

$\mathrm{Y}_{\mathrm{ij}}=\mathrm{Wir}_{\mathrm{ij}}$

$\mathrm{i}=1,2,3, \ldots \mathrm{m} ;$ dan $\mathrm{j}=1,2,3, \ldots \mathrm{n}$

3. Menentukan matriks solusi ideal positif dan matriks solusi ideal negatif.

Solusi ideal positif $\left(\mathrm{A}^{+}\right)$dihitung berdasarkan :

$\mathrm{A}^{+}=\left(\mathrm{y} 1^{+}, \mathrm{y} 2^{+}, \ldots, \mathrm{yn}^{+}\right)$

Solusi ideal positif $\left(\mathrm{A}^{-}\right)$dihitung berdasarkan : 


$$
\mathrm{A}^{-}=\left(\mathrm{y} 1^{-}, \mathrm{y} 2^{-}, \ldots, \mathrm{yn}^{-}\right)
$$

4. Menentukan jarak antar nilai dari setiap alternatif dengan matriks solusi ideal positif dan negatif. Rumus jarak antara alternatif dengan solusi ideal positif :

$\mathrm{D}_{\mathrm{i}}=\sqrt{\sum_{j=1}^{n}\left(y_{i j-} y_{i}^{+}\right), i=1,2,3 \ldots . m}$

Rumus jarak antara alternatif dengan solusi ideal negatif :

$\mathrm{D}_{\mathrm{i}}=\sqrt{\sum_{j=1}^{n}\left(y_{i j-} y_{i}^{-}\right), i=1,2,3 \ldots . m}$

5. Menentukan nilai preferensi untuk setiap alternatif.

$$
\mathrm{V}=\frac{D i^{-}}{D i^{-}+D i^{+}}, i=1,2,3, \ldots . m
$$

Nilai preferensi dari setiap alternatif merupakan hasil akhir dari perhitungan metode TOPSIS, semakin tinggi nilainya maka alternatif tersebut merupakan alternatif yang diinginkan.

\section{B. Metode Simple Additive Weighting}

Metode Simple Additive Weighting ( $S A W$ ) sering juga dikenal dengan istilah metode penjumlahan terbobot. Konsep dasar Metode SAW adalah mencari penjumlahan terbobot dari rating kinerja pada setiap alternatif pada semua atribut [17]. Metode SAW membutuhkan proses normalisasi matriks keputusan (X) ke suatu skala yang dapat diperbandingkan dengan semua rating alternatif yang ada [16].

Adapun langkah penyelesaian suatu masalah menggunakan Metode SAW, yaitu :

1. Menentukan kriteria yang akan dijadikan acuan dalam pengambilan keputusan yaitu $\mathrm{Ci}$

2. Memberikan nilai bobot untuk masing-masing kriteria sebagai $\mathrm{W}$.

3. Memberikan nilai rating kecocokan setiap alternatif pada setiap alternatif.

4. Membuat matriks keputusan berdasarkan kriteria $(\mathrm{Ci})$, kemudian melakukan normalisasi matriks berdasarkan persamaan yang disesuaikan dengan jenis atribut (atribut keuntungan ataupun atribut biaya) sehingga diperolah matriks ternormalisasi $\mathrm{R}$.

$\mathrm{R}_{\mathrm{ij}}=\left\{\begin{array}{l}\frac{x_{i j}}{\operatorname{Max}_{i} x_{i}} \\ \frac{\operatorname{Min}_{i} x_{i j}}{x_{i j}}\end{array}\right\}$

jika j adalah atribut keuntungan (benefit)

jika j adalah atribut biaya (cost)

Keterangan :

$\mathrm{r}_{\mathrm{ij}} \quad=$ Nilai rating kinerja ternormalisasi.

$\mathrm{X}_{\mathrm{ij}} \quad=$ Nilai atribut yang dimiliki dari setiap kriteria.

$\operatorname{Max} X_{i j}=$ Nilai terbesar dari setiap kriteria.

Min $X_{\mathrm{ij}}=$ Nilai terkecil dari setiap kriteria.

Benefit = Jika nilai terbesar adalah terbaik.

5. Hasil akhir diperoleh dari proses perankingan yaitu penjumlahan dan perkalian matriks ternormalisasi $\mathrm{R}$ dengan vector bobot sehingga diperoleh nilai terbesar yang dipilih sebagai alternatif yang baik (Ai) sebagai solusi.

$\mathrm{Vi}=\sum_{j=1}^{n} w_{j} r_{i j}$

Keterangan :

$\mathrm{V}_{\mathrm{i}}=$ rangking untuk setiap alternatif .

$\mathrm{W}_{\mathrm{j}}=$ nilai bobot dari setiap kriteria.

$\mathrm{r}_{\mathrm{ij}}=$ nilai rating kinerja ternormalisasi. 


\section{Result and Analysis}

\subsection{Kriteria Jawaban}

Kriteria ini menentukan bobot dari setiap jawaban dari kuesioner yang dibuat untuk mendapatkan hasil kuantitatif dari Alternatif.

Tabel 1. Nilai Jawaban

\begin{tabular}{rlc} 
No & Keterangan & Bobot \\
\hline 1 & Sangat Setuju & 5 \\
\hline 2 & Setuju & 4 \\
\hline 3 & Netral & 3 \\
\hline 4 & Kurang Setuju & 2 \\
\hline 5 & Tidak Setuju & 1 \\
\hline
\end{tabular}

Nilai dari setiap kriteria dari data sampel adalah :

Tabel 2. Nilai Sampel Data Kriteria

\begin{tabular}{llccccc}
\multirow{2}{*}{ No } & \multirow{2}{*}{ Alternatif } & \multicolumn{5}{c}{ Kriteria } \\
\cline { 3 - 7 } & & K1 & K2 & K3 & K4 & K5 \\
\hline 1 & A1 & 3 & 3 & 3 & 3 & 5 \\
\hline 2 & A2 & 3 & 3 & 5 & 5 & 3 \\
\hline 3 & A3 & 5 & 3 & 3 & 3 & 3 \\
\hline 4 & A4 & 3 & 5 & 3 & 3 & 3 \\
\hline 5 & A5 & 5 & 5 & 2 & 5 & 3 \\
\hline
\end{tabular}

\subsection{Perhitungan Menggunakan Metode TOPSIS}

Perhitungan menggunakan Metode TOPSIS sebagai berikut :

1. Tahap pembuatan matriks ternormalisasi

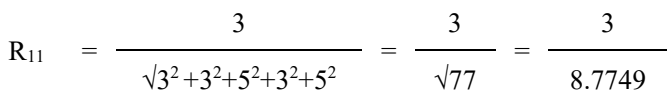

$$
\begin{aligned}
& =0.3418
\end{aligned}
$$

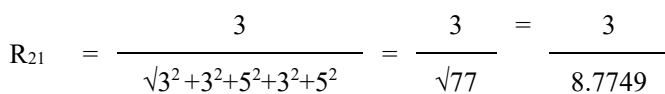

$$
\begin{aligned}
& =0.3418
\end{aligned}
$$

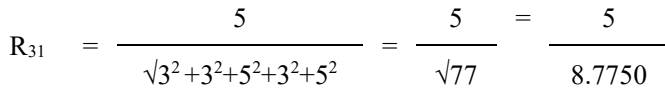

$$
\begin{aligned}
& =0.5698
\end{aligned}
$$

Sehingga menghasilkan data ternormalisasi pada Tabel 3 berikut :

Tabel 3. Data Ternormalisasi

\begin{tabular}{cccccc} 
& K1 & K2 & K3 & K4 & K5 \\
A1 & 0.3419 & 0.3419 & 0.4009 & 0.3419 & 0.6402 \\
\hline A2 & 0.3419 & 0.3419 & 0.6682 & 0.5698 & 0.3841 \\
\hline A3 & 0.5698 & 0.3419 & 0.4009 & 0.3419 & 0.3841
\end{tabular}




\begin{tabular}{llllll}
\hline A4 & 0.3419 & 0.5698 & 0.4009 & 0.3419 & 0.3841 \\
\hline A5 & 0.5698 & 0.5698 & 0.2673 & 0.5698 & 0.3841 \\
\hline
\end{tabular}

2. Tahap menentukan nilai matriks terbobot

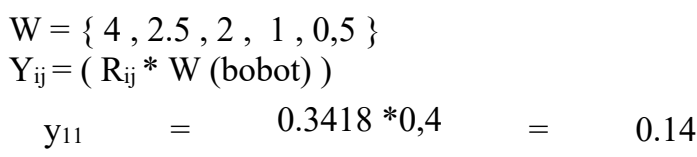

Sehingga menghasilkan data terbobot sebagaimana pada Tabel 4 berikut :

Tabel 4. Data Terbobot

\begin{tabular}{cccccc}
\hline & K1 & K2 & K3 & K4 & K5 \\
A1 & 0.1368 & 0.0855 & 0.0802 & 0.0342 & 0.0320 \\
\hline A2 & 0.1368 & 0.0855 & 0.1336 & 0.0570 & 0.0192 \\
\hline A3 & 0.2279 & 0.0855 & 0.0802 & 0.0342 & 0.0192 \\
\hline A4 & 0.1368 & 0.1425 & 0.0802 & 0.0342 & 0.0192 \\
\hline A5 & 0.2279 & 0.1425 & 0.0535 & 0.0570 & 0.0192 \\
\hline
\end{tabular}

3. Menghitung solusi ideal positif dan negatif $\left(\mathrm{A}^{+} \& \mathrm{~A}^{-}\right)$

$\mathrm{A}_{1}{ }^{+}=\max \left(\mathrm{y}_{11}, \mathrm{y}_{21}, \mathrm{y}_{31}, \mathrm{y}_{41}, \mathrm{y}_{51}\right)$

$\mathrm{A}_{1}{ }^{+}=\max (0.1368,0.1368,0.2279,0.1368,0.2270)$

$\mathrm{A}_{1}{ }^{-}=\min \left(\mathrm{y}_{11}, \mathrm{y}_{21}, \mathrm{y}_{31}, \mathrm{y}_{41}, \mathrm{y}_{51}\right)$

$\mathrm{A}_{1}{ }^{-}=\min (0.1368,0.1368,0.2279,0.1368,0.2270)$

Sehingga menghasilkan data pada Tabel 5 sebagai berikut :

Tabel 5. Data Terbobot

\begin{tabular}{llllll}
\hline $\mathbf{A}^{+}$ & 0.2279 & 0.1425 & 0.1336 & 0.0570 & 0.0320 \\
\hline $\mathbf{A}^{-}$ & 0.1368 & 0.0855 & 0.0535 & 0.0342 & 0.0192 \\
\hline
\end{tabular}

4. Jarak alternatif solusi ideal positif dan negatif

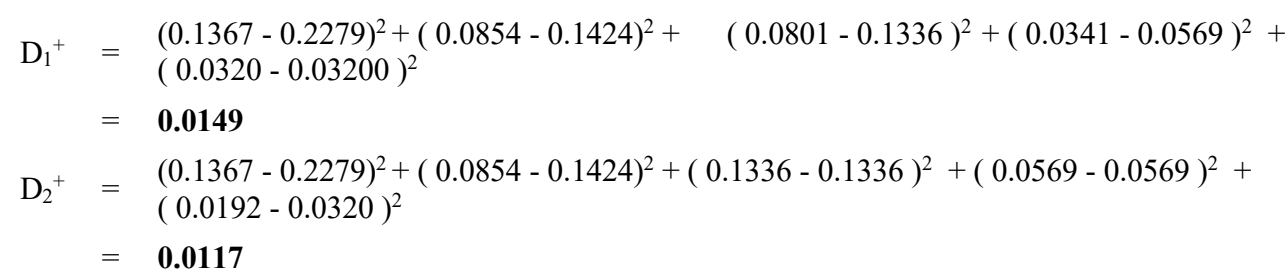

Sehingga menghasilkan solusi ideal pada Tabel 6 sebagai berikut :

Tabel 6. Jarak Solusi Ideal

\begin{tabular}{llllll}
\hline D+ & 0.0149 & 0.0117 & 0.0068 & 0.0119 & 0.0066 \\
\hline D- & 0.0009 & 0.0069 & 0.0090 & 0.0040 & 0.0121 \\
\hline
\end{tabular}

5. Menghitung nilai preferensi 


$$
\begin{array}{llll}
\mathrm{V}_{1} & =\frac{0.0008}{0.0008+0.0149}=0.0555 \\
\mathrm{~V}_{2} & =\frac{0.0069}{0.0069+0.0117}=0.3721 \\
\mathrm{~V}_{3} & =\frac{0.0090}{0.0090+0.0067}=0.5708 \\
\mathrm{~V}_{4} & =\frac{0.0039}{0.0039+0.0118}=0.2505 \\
\mathrm{~V}_{5} & =\frac{0.0120}{0.0120+0.0065}=0.6469
\end{array}
$$

Hasil perangkingan terbesar adalah $\mathrm{V}_{5}$ (Explore Menjangan dan Baluran) sebagai trip yang paling direkomendasikan untuk dipilih. Dengan urutan perangkingan A5, A3, A2, A4, dan A1.

\subsection{Perhitungan Menggunakan Metode SAW}

Perhitungan dengan menggunakan Metode SAW sebagai berikut :

1. Menentukan data ternormalisasi terhadap setiap kriteria.

$\mathrm{R}_{11}=3 / \max \{3,3,5,3,5\}=0.6$

$\mathrm{R}_{21}=3 / \max \{3,3,5,3,5\}=0.6$

Sehingga menghasilkan data pada Tabel 7 sebagai berikut :

Tabel 7. Data Ternormalisasi

\begin{tabular}{cccccc} 
& K1 & K2 & K3 & K4 & K5 \\
\hline A1 & 0.60 & 0.60 & 0.60 & 0.60 & 1.00 \\
\hline A2 & 0.60 & 0.60 & 1.00 & 1.00 & 0.60 \\
\hline A3 & 1.00 & 0.60 & 0.60 & 0.60 & 0.60 \\
\hline A4 & 0.60 & 1.00 & 0.60 & 0.60 & 0.60 \\
\hline A5 & 1.00 & 1.00 & 0.40 & 1.00 & 0.60 \\
\hline
\end{tabular}

2. Menentukan nilai rangking preferensi berdasarkan kriteria yang dibutuhkan $\mathrm{W}=\{4,2.5,2,1,0,5\}$

$$
\begin{aligned}
& \mathrm{V}_{1}=(0,60 * 0,40)+(0,60 * 0,25)+(0.60 * 0,20)+(0.60 * 0,10)+(1 * 0,05)=0,62 \\
& \mathrm{~V}_{2}=(0,60 * 0,40)+(0,60 * 0,25)+(1 * 0,20)+(1 * 0,10)+(0.60 * 0,05)=0,72 \\
& \mathrm{~V}_{3}=(1 * 0,40)+(0,60 * 0,25)+(0.60 * 0,20)+(0.60 * 0,10)+(0.60 * 0,05)=0,76 \\
& \mathrm{~V}_{4}=(0,60 * 0,40)+(1 * 0,25)+(0.60 * 0,20)+(0.60 * 0,10)+(0.60 * 0,05)=0,70 \\
& \mathrm{~V}_{5}=(1 * 0,40)+(1 * 0,25)+(0.40 * 0,20)+(1 * 0,10)+(0,60 * 0,05)=0,86
\end{aligned}
$$

Hasil rangking preferensi tertinggi adalah $\mathrm{V}_{5}$ (Explore Menjangan dan Baluran) sebagai trip yang paling direkomendasikan untuk dipilih. Urutan perangkingannya adalah A5, A3, A2, A4, dan A1. 


\subsection{Analisa Perbandingan} berikut :

Hasil perhitungan dari Metode TOPSIS dan Metode SAW diperoleh hasil sebagamana pada Tabel 8, sebagai

Tabel 8. Analisa Perbandingan

\begin{tabular}{cccc}
\multicolumn{1}{c}{ No } & Alfternatif & SAW & TOPSIS \\
\hline 1 & A1 & 0.62 & 0.0555 \\
\hline 2 & A2 & 0.72 & 0.3721 \\
\hline 3 & A3 & 0.76 & 0.5708 \\
\hline 4 & A4 & 0.70 & 0.2505 \\
\hline 5 & A5 & 0.86 & 0.6469 \\
\hline
\end{tabular}

\section{Conclusion}

Berdasarkan penelitian yang telah dilakukan dapat disimpulkan bahwa Metode TOPSIS dan Metode SAW dapat digunakan untuk proses pengambilan keputusan dalam pemilihan destinasi wisata di Jawa Timur, dengan hasil Explore Baluran dan Menjangan menjadi pilihan yang paling direkomendasikan sebagai pilihan utama. Selain itu diketahui pula bahwa terdapat kesesuaian hasil antara Metode TOPSIS dan SAW, dengan hasil perhitungan dengan menggunakan metode TOPSIS yaitu 0,64 dan perhitungan menggunakan metode SAW adalah 0,86 sebagai nilai hasil perhitungan yang tertinggi. Sehingga dengan demikian, kedua metode ini dapat dinyatakan sama baiknya digunakan dalam proses penentuan destinasi wisata di Jawa Timur. Akan tetapi ini berlaku hanya pada nilai tertingi saja, sebab untuk urutan dua dan seterusnya, hasil perhitungan pada kedua metode ini menunjukan perbedaan dalam rangking.

\section{References}

[1] Indonesia.go.id, "Jawa Timur,” 2019. [Online]. Available: https://indonesia.go.id/province/jawa-timur.

[2] E. Suryowati, "Pertumbuhan Ekonomi Jatim Lampaui Nasional Berkat Pariwisata," 2019. [Online]. Available: https://www.jawapos.com.

[3] V. Dimyati, "Unggul Bidang Pariwisata, Deretan Daerah Ini Dianugerahi Penghargaan,” 2019. [Online]. Available: www.inews.id.

[4] BPS, "Kunjungan Wisman ke Jawa Timur melalui Juanda pada Juli 2019 Naik Sebesar 8,61 persen,” Surabaya, 2019.

[5] A. Triyudanto, "Pengertian Backpaker," 2019. [Online]. Available: www.backpackerindonesia.com.

[6] R. A. Prakoso and Djunaidi, "Komparasi Metode SAW dan TOPSIS untuk Menentukan Prioritas Perbaikan Jalan," J. Tek. Elektro, vol. 8, no. 1, pp. 8-11, 2016.

[7] M. A. Mude, "Perbandingan Metode SAW dan TOPSIS Pada Kasus UMKM," J. Ilm. Ilk., vol. 8, no. 2, pp. 76$81,2016$.

[8] J. A. D. Guterres, "Pemanfaatan Metode SAW dan TOPSIS Sebagai Media Pendukung Keputusan Pemberian Bantuan Rumah Layak Huni," Pros. SINTAK 2017, pp. 51-56, 2017.

[9] A. B. Paksi, E. Utami, and Henderi, "Penerapan SAW-TOPSIS Dalam Analisis Rasio Keuangan Untuk Menunjang Keputusan Berinvestasi Saham,”Semin. Nas. Teknol. Inf. dan Multimed. 2017, pp. 19-24, 2017.

[10] L. N. Ariyana, Renna Yanwastika; Nurnawati, Erna Kumalasari; El Suffa, "Kombinasi Metode TOPSIS dan SAW Dalam Mendukung Keputusan Seleksi Kelayakan Proposal Penelitian Dosen,” Pros. Semin. Nas. Apl. Sains Teknol. 2018, no. September, pp. 141-150, 2018.

[11] A. A. Azhari, A. Najib, and T. Informasi, "Perbandingan Metode SAW dan TOPSIS Pada Penerimaan Siswa Praktek Kerja Lapangan,” Pros. Semin. Nas. Ilmu Komput. dan Teknol. Inf. 2018, vol. 3, no. 1, pp. 71-77, 2018.

[12] Fatkhurrochman and D. Astuti, “Analisis Perbandingan Metode TOPSIS Dan SAW Dalam Penentuan Penerima Bantuan Pengembangan Rumah Masyarakat Kurang Mampu,” Semin. Nas. Teknol. Inf. dan Multimed. 2018, pp. 67-72, 2018.

[13] H. Wibowo S, "MADM-Tool : Aplikasi Uji Sensitivitas Untuk Model MADM Menggunakan Metode SAW dan TOPSIS," Semin. Nas. Apl. Teknol. Inf., vol. 0, no. 0, 2010.

[14] C. Hwang and K. Yoon, Multiple Attribute Decision Making: Methods and Applications, A State of the Art Survey. 1981

[15] A. Saleh, R. E. Sari, and H. Kurniawan, "Metode Fuzzy Simple Additive Weighting (SAW) Dalam Menentukan Kualitas Kulit Ular Untuk Kerajinan Tangan (Studi Kasus : CV . Asia Exotica Medan)," Semin. Nas. Inform., pp. 18-23, 2014.

[16] D. Nofriansyah and S. Akba, Konsep Data Mining Vs Sistem Pendukung Keputusan. Yogyakarta: Deepublish, 
2015.

[17] E. A. Riyanto and T. Haryanti, "Sistem Pendukung Keputusan Pemilihan Teller Pooling Terbaik Pada PT. BCA, Tbk. Dengan Motode SAW (Simple Additive Weighting),” J. Pilar Nusa Mandiri, vol. 13, no. 1, pp. 128-135, 2017. 